\title{
Enhanced Adsorption of Selenium Ions from Aqueous Solution Using Iron Oxide Impregnated Carbon Nanotubes
}

\author{
Omer Y. Bakather, ${ }^{1,2}$ Ahmad Kayvani Fard, ${ }^{3,4}$ Ihsanullah, ${ }^{5}$ Majeda Khraisheh, ${ }^{6}$ \\ Mustafa S. Nasser, ${ }^{7}$ and Muataz Ali Atieh ${ }^{3,4}$ \\ ${ }^{1}$ Department of Chemical Engineering, Jazan University, P.O. Box 706, Jazan 45142, Saudi Arabia \\ ${ }^{2}$ Department of Chemical Engineering, Hadhramout University, Hadhramout, Yemen \\ ${ }^{3}$ Qatar Environment and Energy Research Institute, Hamad Bin Khalifa University, Qatar Foundation, P.O. Box 5825, Doha, Qatar \\ ${ }^{4}$ College of Science and Engineering, Hamad Bin Khalifa University, Qatar Foundation, P.O. Box 5825, Doha, Qatar \\ ${ }^{5}$ Department of Chemical Engineering, King Fahd University of Petroleum \& Minerals, Dhahran 31261, Saudi Arabia \\ ${ }^{6}$ Chemical Engineering Department, Qatar University, P.O. Box 2713, Doha, Qatar \\ ${ }^{7}$ Gas Processing Centre, College of Engineering, Qatar University, P.O. Box 2713, Doha, Qatar
}

Correspondence should be addressed to Muataz Ali Atieh; mhussien@hbku.edu.qa

Received 5 February 2017; Revised 12 March 2017; Accepted 28 March 2017; Published 7 May 2017

Academic Editor: Spyros P. Perlepes

Copyright (C) 2017 Omer Y. Bakather et al. This is an open access article distributed under the Creative Commons Attribution License, which permits unrestricted use, distribution, and reproduction in any medium, provided the original work is properly cited.

The aim of this research was to investigate the potential of raw and iron oxide impregnated carbon nanotubes (CNTs) as adsorbents for the removal of selenium (Se) ions from wastewater. The original and modified CNTs with different loadings of $\mathrm{Fe}_{2} \mathrm{O}_{3}$ nanoparticles were characterized using high resolution transmission electron microscopy (HRTEM), scanning electron microscopy (SEM), X-ray diffractometer (XRD), Brunauer, Emmett, and Teller (BET) surface area analyzer, thermogravimetric analysis (TGA), zeta potential, and energy dispersive X-ray spectroscopy (EDS). The adsorption parameters of the selenium ions from water using raw CNTs and iron oxide impregnated carbon nanotubes $\left(\mathrm{CNT}-\mathrm{Fe}_{2} \mathrm{O}_{3}\right)$ were optimized. Total removal of $1 \mathrm{ppm}$ Se ions from water was achieved when $25 \mathrm{mg}$ of CNTs impregnated with $20 \mathrm{wt} . \%$ of iron oxide nanoparticles is used. Freundlich and Langmuir isotherm models were used to study the nature of the adsorption process. Pseudo-first and pseudo-second-order models were employed to study the kinetics of selenium ions adsorption onto the surface of iron oxide impregnated CNTs. Maximum adsorption capacity of the $\mathrm{Fe}_{2} \mathrm{O}_{3}$ impregnated CNTs, predicted by Langmuir isotherm model, was found to be $111 \mathrm{mg} / \mathrm{g}$. This new finding might revolutionize the adsorption treatment process and application by introducing a new type of nanoadsorbent that has super adsorption capacity towards Se ions.

\section{Introduction}

Selenium (Se) is unique nonmetal chemical element with five known oxidative states under the form of elemental selenium $\mathrm{Se}^{0}$, namely, $0,{ }^{-} 1,{ }^{-} 2,{ }^{+} 4$, and ${ }^{+} 6[1]$. Although it is an important trace element for many organisms, exceeding homeostatic levels is considered toxic. Se is typically found on the earth's crust, rocks, and sedimentary soils [2]. Recent reports state that a significant amount of Se emissions into the atmosphere and aquatic environment is related to industrial and mining activities in addition to agricultural drainage run-off [3-5].
Tan et al. [6], in a recent extensive review, reported the different types of organic and inorganic Se species available. The inorganic form of Se is typically found in surface and ground water in a number of reported forms such as $\mathrm{Se}^{-2}$ (selinide), $\mathrm{SeO}_{3}{ }^{-2}$ (selenite), $\mathrm{SeO}_{4}{ }^{-2}$ (selenate), and $\mathrm{Se}^{0}$, which is the species nonsoluble form. If found in high concentration levels in waste or surface water, Se can cause serious environmental problems $[7,8]$. The maximum level for Se in surface water was set at $5.0 \mu \mathrm{g} / \mathrm{L}$ by the United States Environmental Protection Agency (USEPA) in 1999. Therefore, due to the increased interest in Se treatment and the more 
stringent environmental consent levels for its concentration in surface water, the value set in 1999 is being updated by USEPA in $2014[1,5,9]$. Furthermore, there is variation in the maximum allowable levels of Se in drinking water worldwide. According to the World Health Organization [10] the value is set at $40 \mu \mathrm{g} / \mathrm{L}$, while the European Union (EU) sets the Se levels at a much lower value of $10 \mu \mathrm{g} / \mathrm{L}$ [11]. In order to meet the drinking water standards for Se in addition to treating industrial, mining wastewaters and agricultural runoffs, a varied number of treatment processes are reported in the open literature with various degrees of complexity and advancement. Comprehensive reviews conducted by Robberecht and Van Grieken [4] and Tan et al. [6] offer an excellent overview of all current known treatments used for Se. It can be seen from the two recent reviews that although a great variety of biological [12-14], chemical [15-20], and physical treatments technologies $[9,21,22]$ were developed in recent years, no single treatment offers a complete and cost effective scheme for treating Se from waste or drinking water. While biological treatments stand as one of the best options for treating Se, challenges related to long-term stability of the biogenic selenium and the predicting of the fate of the bioreduced Se in the environment are two major concerns. On the other hand, adsorption has been reported as an effective lower cost treatment technology for Se removal [23]. Varied adsorbents have been tested including low cost alternative materials [4], activated carbons, and other metal-oxide-enhanced materials. Of the latter, metal-oxideenhanced materials with ferrihydrite have been reported as the most promising materials for the treatment of water containing $\mathrm{SeO}_{3}{ }^{-2}$ ions [16]. Reports showed that the strong affinity of $\mathrm{SeO}_{3}{ }^{-2}$ to iron hydroxide surfaces resulted in around $99 \%$ removal rate for a wide $\mathrm{pH}$ range (3-8). In contrast, the process was not effective for $\mathrm{SO}_{4}{ }^{-2}$ and its presence acted as a competitor for the desorption sites causing suppressed removal rates [20]. The inadequate $\mathrm{SO}_{4}{ }^{-2}$ removal was also related to interacting between the various $\mathrm{Se}$ species and the surface of the adsorbent. While $\mathrm{SeO}_{3}{ }^{-2}$ was reported to form inner-sphere adsorption on iron hydroxide adsorbents, $\mathrm{SO}_{4}{ }^{-2}$, on the other hand, was adsorbed in an outer sphere manner resulting in an ineffective removal [16]. Accordingly, the development of a process to remove effectively most of the possible inorganic forms of $\mathrm{Se}$ is still required. With this in mind and due to their high surface areas, recent studies reported the use of various nanomaterials for the removal of the Se oxyanions. Example such as hydrophilic magnetic nanoparticle-graphene oxide composite was reported recently by Fu et al. [16]. A twostep reaction was used in the preparation of the adsorbents in addition to deposition of iron oxide nanoparticles at high temperatures. The authors reported a maximum removal of $95 \%$ of $\mathrm{Se}(\mathrm{VI})$ ions at $\mathrm{pH} \sim 2$. While it is not easy to compare the maximum capacity of an adsorbent for the Se removal given the varied preparation methods, costs, and experimental condition, a recent study using a new iron oxide nanoparticles reported a higher removal rates compared with literature reported values [18]. Having said that, the values are still small and the search for other adsorbents is still required for cost effective Se removal from water.
Accordingly, this study is focused on developing multiwalled carbon nanotubes based novel materials for effective removal of Se from aqueous solutions. In recent years, multiwalled carbon nanotubes (CNTs) have been explored widely due to their unique properties [24-26] and have been extensively used in nanotechnology, optics, electronics, material science, and water treatment [27]. CNTs were also reported for the adsorption of heavy metal ions [28-32] and organic compounds [33-36]. Despite the most recent comprehensive review articles and to the best of our knowledge, no studies were reported on the use of multiwalled carbon nanotubes for Se removal. In this work, iron oxide impregnated CNTs were employed for the adsorption of the selenium ions from water. The effect of iron oxide loading, $\mathrm{pH}$, dosage of CNTs, contact time, and initial concentration were studied on the removal of selenium. The raw CNTs and impregnated CNTs were characterized using field emission scanning electron microscopy (FE-SEM), high transmission electron microscopy (HR-TEM), thermogravimetric analysis (TGA), X-ray diffractometer (XRD), energy dispersive X-ray spectroscopy (EDS), Brunauer, Emmett, and Teller (BET) nitrogen adsorption technique, and zeta potential. The adsorption equilibrium data were correlated by the Langmuir and Freundlich isotherms and the kinetic data were analyzed using two kinetic models.

\section{Experimental}

2.1. Materials. All solvents used in this study were of analytical grade and purchased from Sigma-Aldrich Co. Ltd. Ethanol liquid (98\%, purity) was used as a solvent and iron (III) nitrate as a precursor of iron nanoparticles and selenium dioxide $\left(\mathrm{SeO}_{2}\right)$ was used as source of selenium ions in the water.

2.2. Production of Carbon Nanotubes. Floating catalyst chemical vapor deposition reactor was used for the production of CNTs. The experimental setup used and reaction conditions are reported previously by Fard et al. [26]. Briefly, injected vertical chemical vapor deposition (FC-CVD) with quartz tube $100 \mathrm{~mm}$ in diameter and $1200 \mathrm{~mm}$ in length with flanges fixed at both ends was used to synthesis CNTs. Xylene was used as source of hydrocarbon and the argon gas was used to flush the air from the system, while the hydrogen gas was used as a carrier and reacting gas. Purity of CNTs produced was $>96 \%$.

\subsection{Impregnation of CNTs. The iron oxide nanoparticles were} impregnated on the surface of CNTs by a wet impregnation method. For 5\% iron oxide loadings, $361 \mathrm{mg}$ of Iron (III) nitrate nonahydrate and $1 \mathrm{~g}$ of CNTs were dissolved separately in ethanol solution and sonicated for 30 minutes to ensure uniform mixing. Upon further mixing of the two solutions and further sonication, the solution was kept in a furnace at $80^{\circ} \mathrm{C}$ overnight to evaporate the ethanol. Finally, the product was calcined at $350^{\circ} \mathrm{C}$ for 3 hours in the convection oven to ensure effective attachment of the iron oxide particles onto the surface of CNTs. After cooling, the composite of CNTs 
with $5 \%$ iron oxide NP is synthesized. To produce CNTs with $10 \%$ and $20 \%$ iron oxide loading, $722 \mathrm{mg}$ and $1.44 \mathrm{~g}$ Iron (III) nitrate nonahydrate are mixed with $1 \mathrm{~g}$ of CNTs, respectively. Details of the preparation are found elsewhere [37].

\subsection{Characterization of Carbon Nanotubes}

2.4.1. Crystal Structure. Powder X-ray diffraction (XRD) patterns were recorded using a Rigaku MiniFlex-600. The X-ray diffractometer with $\mathrm{Cu} \mathrm{K} \alpha$ radiation $\lambda=1.54 \AA$ at a rate of $0.4 \%$ over Bragg angles ranging from 10 to $90^{\circ}$ was used for the analysis. The operating voltage and current were maintained at $40 \mathrm{kV}$ and $15 \mathrm{~mA}$, respectively.

2.4.2. Surface Structure. Scanning electron microscopy (SEM) was performed using FEI Quanta 200 Environmental Scanning Electron Microscope (ESEM) with a resolution of $5 \mathrm{~nm}$ and magnification $200 \mathrm{~K}$ to observe the morphology and structure of the material. Also, the morphological and structural analysis of CNTs was conducted using transmission electron microscopy (TEM) (CM12, Philips).

2.4.3. Point of Zero Charge. To measure the surface charge and zeta potential Zetasizer (Nano ZS 90, Malvern Instruments Ltd., Malvern, UK) equipped with a $4.0 \mathrm{~mW}$ internal laser was used. The Zetasizer works on the principle of dynamic light scattering (DLS). The measurements were performed at room temperature $\left(25^{\circ} \mathrm{C}\right)$ with a scattering angle of $90^{\circ}$.

2.4.4. Other Chemical Properties and Surface Area. To analyze physical and chemical properties of CNTs with respect to temperature, the thermogravimetric analyses were performed using a TGA analyzer (SDT, Q600) at a heating rate of $10^{\circ} \mathrm{C} / \mathrm{min}$ in air. The surface areas of CNTs were measured by $\mathrm{N}_{2}$ adsorption at $77 \mathrm{~K}$ using BET surface area analyzer (Micromeritics ASAP 2020).

2.5. Preparation of the Selenium Stock Solution. Specific amount of $\mathrm{SeO}_{2}$ was dissolved in deionized water to prepare the stock solution. $\mathrm{SeO}_{2}$ dissolves in water to form selenous acid $\left(\mathrm{SeO}_{2}{ }^{-3}\right)$. The $\mathrm{pH}$ of the stock solution was adjusted by using $0.1 \mathrm{M} \mathrm{NaOH}$ or $0.1 \mathrm{M} \mathrm{HNO}_{3}$ and maintained by the addition of buffer solutions.

2.6. Se Sorption Experiments. In order to assess the effectiveness of the new adsorbent, batch adsorption experiments were conducted at room temperature in $1 \mathrm{~L}$ glass beakers. $50 \mathrm{~mL}$ of selenium solution of required concentration was placed in the flasks, covered, and mounted on the mechanical rotary shaker (MPI Lab Shaker) to ensure adequate mixing. Different experimental runs were conducted to study the effect of solution $\mathrm{pH}$, contact time, CNTs dosage, and initial Se (IV) ions concentration on the adsorption of Se ions. Inductively coupled plasma mass spectroscopy (ICP-MS) was employed to analyze the concentrations of the samples. The adsorption capacity $(Q)$ and removal efficiency (RE) were calculated as follows [37]:

$$
Q=\frac{\left(C_{i}-C_{f}\right) \times V}{W_{g}}
$$

$$
\operatorname{RE}(\%)=\frac{\left(C_{i}-C_{f}\right)}{C_{i}} \times 100,
$$

where $C_{i}(\mathrm{mg} / \mathrm{L})$ is the initial concentration of selenium in the water, $C_{f}(\mathrm{mg} / \mathrm{L})$ is the final concentration of the selenium in the water, $V(\mathrm{~L})$ is the volume of the water, and $W_{g}$ is the mass of CNTs.

2.7. Adsorption Isotherms Models. The Langmuir and Freundlich isotherms were used to study the adsorption performance and to determine the adsorption capacity for the adsorbent [37]. The Langmuir adsorption isotherm is expressed as follows:

$$
Q_{e}=\frac{q_{m} K_{L} C_{e}}{1+K_{L} C_{e}},
$$

where $Q_{e}(\mathrm{mg} / \mathrm{g})$ and $q_{m}(\mathrm{mg} / \mathrm{g})$ are the amount adsorbed at equilibrium and the maximum adsorption capacity, respectively, while $C_{e}(\mathrm{mg} / \mathrm{L})$ is the equilibrium adsorbate concentration and $K_{L}$ is Langmuir constant.

Equation (2) can be linearized as follows:

$$
\frac{C_{e}}{Q_{e}}=\frac{C_{e}}{q_{m}}+\frac{1}{K_{L} q_{m}} .
$$

Freundlich isotherm is expressed as follows:

$$
Q_{e}=K_{f} C_{e}^{1 / n}
$$

Equation (4) can be linearized as follows:

$$
\log Q_{e}=\frac{1}{n} \log C_{e}+\log K_{f}
$$

where $n$ and $K_{f}$ are the empirical constants.

2.8. Adsorption Kinetics. In order to find the maximum selenium removal by CNTs and to model the experimental data, two well-known kinetic models, pseudo-first-order and pseudo-second-order models, were used in this study.

The Lagergren pseudo-first-order model proposes that the rate of sorption is proportional to the number of sites unoccupied by the adsorbate [37]. The linear form of the pseudo-first-order equation can be expressed as follows:

$$
\ln \left(Q_{e}-Q_{t}\right)=\ln Q_{e}-k_{1} t
$$

where $Q_{t}$ is the sorption capacity $(\mathrm{mg} / \mathrm{g}$ ) at any preset time interval $(t)$ and $k_{1}$ is the pseudo-first-order rate constant $\left(\mathrm{min}^{-1}\right)$. A graph of $\ln \left(Q_{e}-Q_{t}\right)$ versus time is plotted and the constant is found. Additionally, the adsorption data 


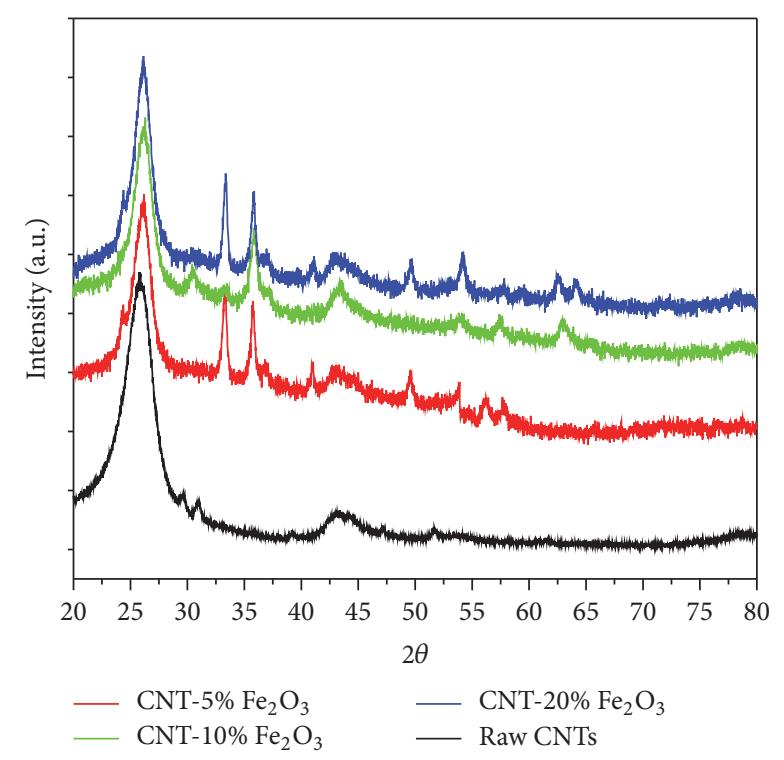

FIGURE 1: XRD analysis of raw CNTs, and CNT-5\% iron oxide, CNT$10 \%$ iron oxide, and CNT-20\% iron oxide.

were modeled to the pseudo-second-order kinetic model [37] where its linear form is expressed as follows:

$$
\frac{t}{Q_{t}}=\frac{1}{k_{2} Q_{e}^{2}}+\frac{t}{Q_{e}}
$$

where $k_{2}$ is the pseudo-second-order rate constant (g/mg-min). By plotting $t / Q_{t}$ versus time, straight lines were obtained and the constants, $k_{2}$ and $Q_{e}$, were found.

\section{Results and Discussion}

3.1. Characterization of Carbon Nanotubes. Figure 1 shows the X-ray diffraction patterns of CNTs and impregnated CNTs with $\mathrm{Fe}_{2} \mathrm{O}_{3}$ nanoparticles. The XRD diffraction pattern of pure $\alpha-\mathrm{Fe}_{2} \mathrm{O}_{3}$ is similar to that of CNTs impregnated $\mathrm{Fe}_{2} \mathrm{O}_{3}$ nanoparticles confirming the presence of $\alpha-\mathrm{Fe}_{2} \mathrm{O}_{3}$ crystal nanoparticles on the surfaces of CNTs. The distinct peaks of $\alpha-\mathrm{Fe}_{2} \mathrm{O}_{3}$ crystalline structure are found at $2 \theta$ of $34,36,42$, $50,54,63,65,72$, and 75 . The characteristic peak of CNTs was observed at $2 \theta$ of 27 which corresponds to $\mathrm{C}(002)$ and indicative of proper and undamaged graphite structure of the CNTs. The other characteristic diffraction peaks of graphite are at $2 \theta$ of $43^{\circ}, 45^{\circ}$, and $77^{\circ}$ and associated with C (100), C (101), and $\mathrm{C}$ (110) diffractions of graphite, respectively. Peaks indexed at C (002), C (100), and C (101) are indication of hexagonal structure of CNTs and the presence of $\mathrm{C}(002)$ peak in the XRD data confirms the multiwalled nature of the carbon nanotubes [42].

The sharp peak at the $2 \theta$ of $25.5^{\circ}$ of the raw and impregnated CNTs is indicative of undamaged (no impurities in lattice) and developed graphite structure. Defects would have been observed in the CNTs if the $2 \theta$ peak of $25.5^{\circ}$ was broader and a shift of the peak diffraction towards lower angles was detected. Peaks at 31, 44, and 52.5 are indicative of the multiwalled nature of the carbon nanotubes. The results observed by the peaks in Figure 1 are a clear testament to the highly crystalline, uniform, highly ordered, and pure CNTs. The results here are further confirmed by SEM and TEM images.

In addition to XRD, the raw and impregnated CNTs were characterized further using field-scanning electron microscopy (FE-SEM), high resolution transmission electron microscopy (HR-TEM), thermogravimetry (TGA) techniques, XRD, BET surface area, and zeta potential.

The morphologies of these samples were obtained by SEM as shown in Figure 2. The diameter of the CNTs, with spongelike structure, varied from 20 to $50 \mathrm{~nm}$ with an average diameter of $25 \mathrm{~nm}$. The surface of CNTs after impregnation with $\mathrm{Fe}_{2} \mathrm{O}_{3}$ showed no surface changes and appeared to be agglomerated and untangled.

High resolution transmission electron microscopy (HRTEM) was carried out to characterize the size, structure, and purity of the iron oxide nanoparticles doped and virgin CNTs. The raw CNTs TEM image presented in Figure 3 clearly indicates a highly ordered CNTs crystalline structure with diameter ranging from 10 to $30 \mathrm{~nm}$ and length from 10 to $30 \mu \mathrm{m}$. In addition, it can be noted that the clear fringes of the graphitic sheets are well separated by $0.35 \mathrm{~nm}$ and are aligned with a tilted angle of about $2^{\circ}$ toward the tube axis. The TEM images of CNTs doped with $\mathrm{Fe}_{2} \mathrm{O}_{3}$ nanoparticles are presented in Figures 3(b)-3(d) in order to substantiate the presence of iron oxide nanoparticle on the surfaces of CNTs. The white iron oxide nanoparticles with some spherical and irregular shapes are shown in the TEM images. The size of $\mathrm{Fe}_{2} \mathrm{O}_{3}$ nanoparticles is estimated to be around $1-5 \mathrm{~nm}$ which are somehow distributed evenly and on some locations agglomerated slightly causing increase in the nanoparticle size.

To confirm the presence of iron oxide and also to experimentally find out the percentage of iron oxide nanoparticles on surface of CNTs, EDS analysis was conducted and the results are shown in Table 1.

The $\mathrm{Fe}_{2} \mathrm{O}_{3}$ content of the impregnated CNTs was also investigated using TGA. The experiment was carried out using air at a heating rate of $10^{\circ} \mathrm{C} / \mathrm{min}$. The thermograms are shown in Figure 4. Under this operating condition, the raw CNTs decomposed and oxidized completely as verified by the TGA curve in Figure 4. As $\mathrm{Fe}_{2} \mathrm{O}_{3}$ content on surface of CNTs increased, higher residual yield was found which corresponded to the presence of iron oxide NPs on the surface of CNT [37]. TGA provides an accurate estimate of the loading of iron oxide NPs doped on surface of CNTs by comparing the residues for the complete oxidation of the raw and impregnated CNTs. Therefore, CNTs with $1 \%, 10 \%$, and $20 \% \mathrm{Fe}_{2} \mathrm{O}_{3}$ loading had residual yields of $6 \mathrm{wt} . \%, 8 \mathrm{wt} . \%$, and $17 \mathrm{wt} . \%$, respectively. Moreover it can be noted that the increase in $\mathrm{Fe}_{2} \mathrm{O}_{3}$ NP loading resulted in a decrease of the decomposition temperature. It can also be inferred, from the TGA analysis shown in Figure 4, that raw CNTs start to decompose at $540^{\circ} \mathrm{C}$ while the $5 \%, 10 \%$, and $20 \%$ loaded CNTs with $\mathrm{Fe}_{2} \mathrm{O}_{3}$ decomposed at lower temperatures (450, 430, and $410^{\circ} \mathrm{C}$, resp.). According to Chiang et al. [43] the earlier decomposition of CNTs impregnated with metallic NPs can be explained by reduction of the thermal stability of CNTs by 


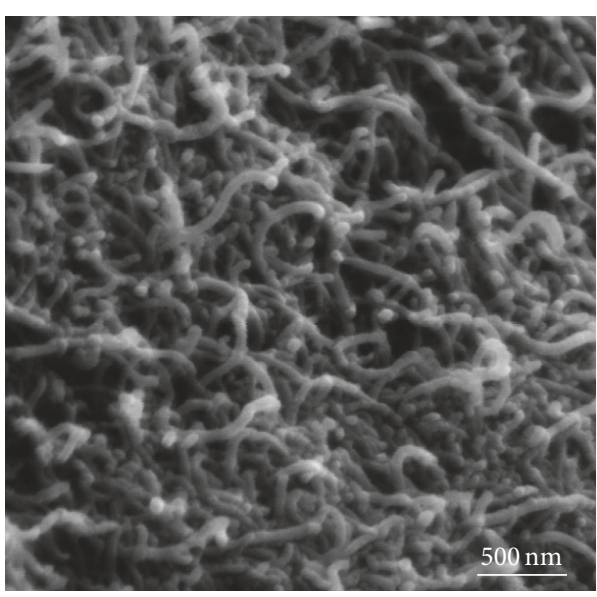

(a)

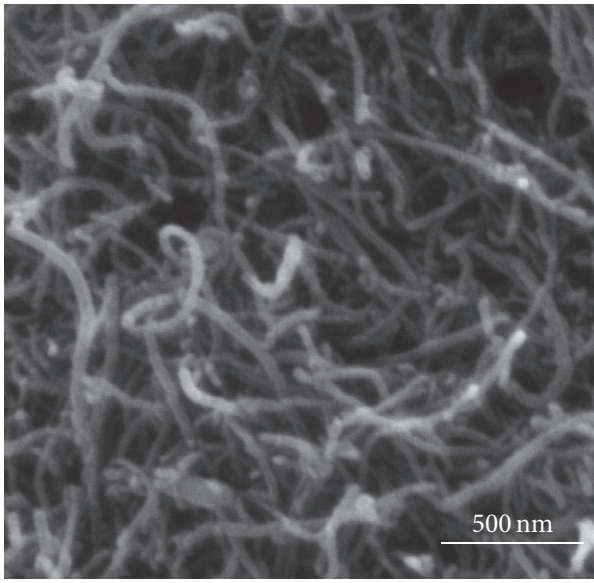

(c)

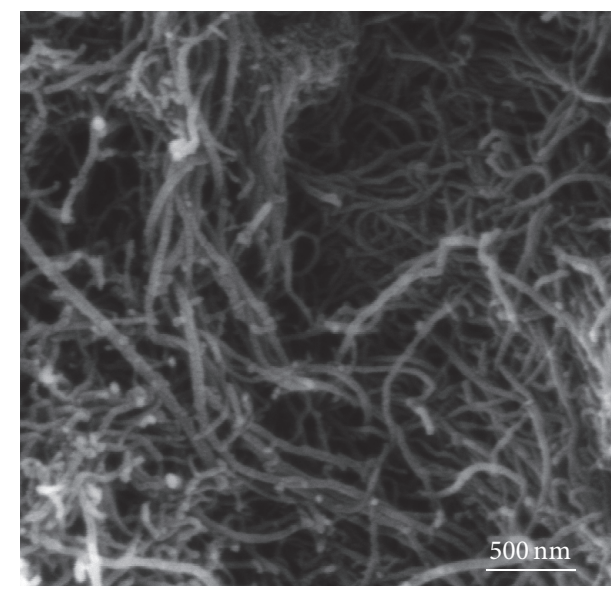

(b)

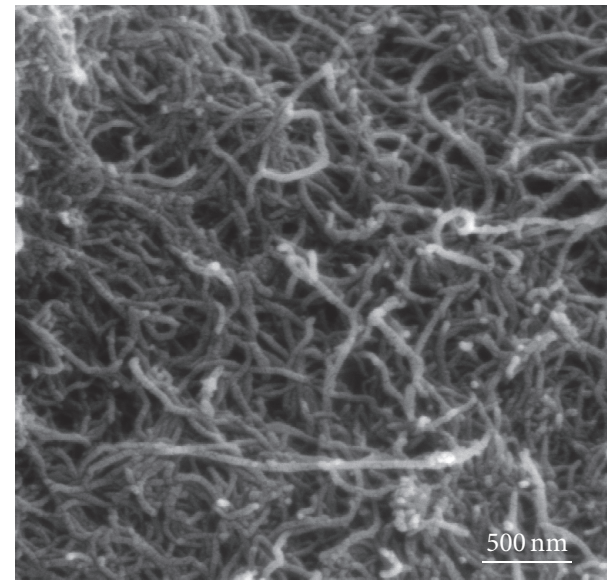

(d)

Figure 2: SEM images of (a) raw CNTs, (b) CNT-5\% iron oxide, (c) CNT-10\% iron oxide, and (d) CNT-20\% iron oxide.

catalyzing the low-temperature oxidation of CNTs. Therefore, it can be inferred that the presence of nanosized iron oxide particles with high surface area altered the thermal stability of the CNTs and catalyzed oxidation of impregnated CNTs under the air compared to the pristine CNTs. The nanosized metallic particles might act as a heating accelerant that progresses the heat transfer to the surface of the CNTs and enhance the oxidation process.

The surface area of raw CNTs and impregnated CNTs was measured using BET surface area analyzer. As shown in Figure 5, the surface area of raw CNTs and CNTs impregnated with $5 \%, 10 \%$, and $20 \%$ iron oxide nanoparticles was found to be $137.7,226.6,295.4$, and $360 \mathrm{~m}^{2} / \mathrm{g}$, respectively. The presence of the nanosized iron oxide particles doubled the surface area upon using $20 \mathrm{wt}$ \% iron oxide nanoparticles. Increasing the surface area inherently increases the number of adsorption sites available for the removal of selenium and therefore results in higher adsorption capacity.

Finally, the surface charge of the CNTs and impregnated CNTs with iron oxide nanoparticles was measured and the results are illustrated in Figure 6. When the $\mathrm{Fe}_{2} \mathrm{O}_{3}$ nanoparticles were loaded onto the surface of CNTs the negative sign of zeta potential on the surface of carbon nanotubes decreased due to neutralizing the repulsive effects of the electrical double layers. However, selenium $\left(\mathrm{SeO}_{3}{ }^{2-}\right)$ has very large negative zeta potential $(-0.37 \mathrm{~V})$. As the negative sign of zeta potential decreases, the electrostatic attraction would make and attachment between CNTs and selenium ions more likely [38]. Thus, it is important to decrease the electrostatic repulsion barrier between the selenium ions and CNTs to further improve the adsorption process. It is clear from the zeta potential measurements in Figure 6 that increasing the percentage of $\mathrm{Fe}_{2} \mathrm{O}_{3}$ nanoparticles onto the surface of CNTs caused a reduction in the negative sign of zeta potential. The trends obtained here are in good agreement with the adsorption measurements carried out in this work, where increasing the loading of $\mathrm{Fe}_{2} \mathrm{O}_{3}$ nanoparticle onto the surface of CNTs enhanced the removal of the selenium ions from the water. On the other hand, loading $\mathrm{Fe}_{2} \mathrm{O}_{3}$ NPs onto the surface of CNTs alters the point of zero charge (PZC) of the composite. $\mathrm{PZC}$ is a $\mathrm{pH}$ value at which material has zero zeta potential. Raw CNTs have PZC at pH of 4.6 while CNTs with $5 \%, 10 \%$, and $20 \% \mathrm{Fe}_{2} \mathrm{O}_{3}$ loading have $\mathrm{PZC}$ at $\mathrm{pH}$ of 5.2, 5.6, and 5.9, respectively. 


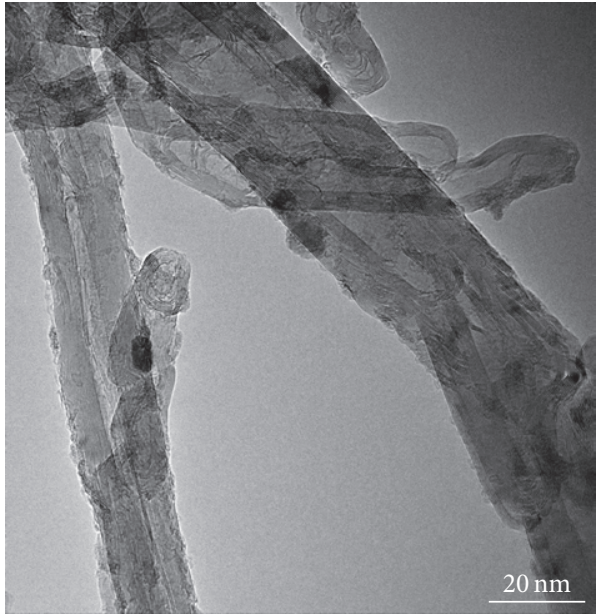

(a)

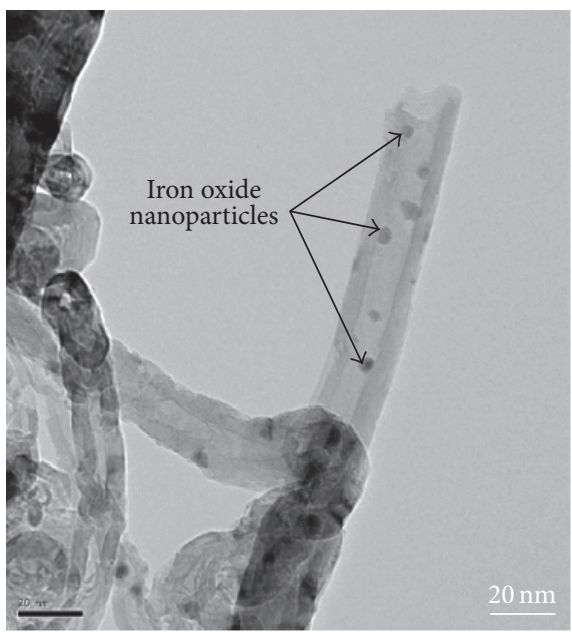

(c)

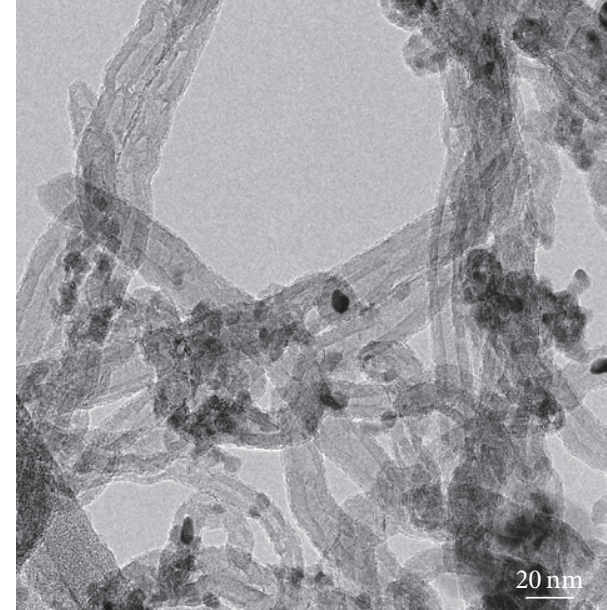

(b)

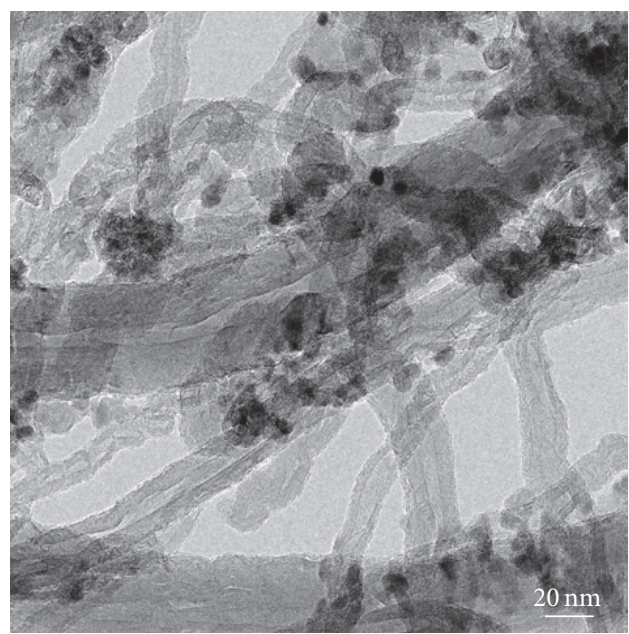

(d)

FIgURE 3: HRTEM images of (a) raw CNTs, (b) CNT-5\% iron oxide, (c) CNT-10\% iron oxide, and (d) CNT-20\% iron oxide.

TABLE 1: EDS analysis of raw CNTs and CNTs with different percentage of $\mathrm{Fe}_{2} \mathrm{O}_{3}$.

\begin{tabular}{lcccc}
\hline CNTs sample Raw CNTs & $\begin{array}{c}\mathrm{CNT}-\mathrm{Fe}_{2} \mathrm{O}_{3} \\
(5 \%)\end{array}$ & $\begin{array}{c}\mathrm{CNT}-\mathrm{Fe}_{2} \mathrm{O}_{3} \\
(10 \%)\end{array}$ & $\begin{array}{c}\mathrm{CNT}-\mathrm{Fe}_{2} \mathrm{O}_{3} \\
(20 \%)\end{array}$ \\
Element & Weight \% & Weight \% & Weight \% & Weight \% \\
\hline C & 98.50 & 91.80 & 84.53 & 56.4 \\
$\mathrm{O}$ & 1.50 & 3.65 & 4.44 & 25.52 \\
$\mathrm{Fe}$ & 0 & 4.55 & 11.03 & 18.08 \\
Total \% & 100 & 100 & 100 & 100 \\
\hline
\end{tabular}

3.2. Effect of $\mathrm{pH}$. The $\mathrm{pH}$ of the solution plays an important role in the adsorption of selenium ions on the adsorbent surface as it is dependent on the surface properties of the impregnated $\mathrm{CNT}$ s and distribution of selenium ions in water.

The effect of $\mathrm{pH}$ on the removal of selenium ions is presented in Figure 7. The adsorption of selenium species was higher at lower $\mathrm{pH}$ and the removal was observed to decrease with increase in $\mathrm{pH}$ for the impregnated CNTs. The maximum removal was observed at $\mathrm{pH} 1$. This higher removal at lower $\mathrm{pH}$ was due to the higher positive surface charges as indicated by zeta potential of the CNTs that favors the adsorption of anion (e.g., $\mathrm{SeO}_{3}{ }^{2-}$ ) [44]. This can be explained by release of $\mathrm{OH}$ ions when anion or weak acid is adsorbed onto hydroxide, which has favor toward adsorption of $\mathrm{SeO}_{3}{ }^{2-}$ at low $\mathrm{pH}$. Zhang et al. [38] used activated carbon doped with iron oxide for the removal of selenium from water. The authors reported that selenium removal sharply dropped after pH 8 and the maximum removal occurred in acidic solutions with $\mathrm{pH}$ between 1 and 3. A similar trend was previously observed in case of selenium ions adsorption on iron oxide nanoparticle [8], iron-coated GAC [38], hematite [45], soil [46], hydroxyapatite [39, 47], goethite and hydrous ferric oxide $[48,49]$, aluminum oxide coated sand [40], metal oxide nanoparticles [50], goethite [51], nanoscale zero-valent iron [52], and cellulose microcolumn [53].

It is anticipated that at lower $\mathrm{pH}$, the adsorbent surface carries a additional positive charge and the anionic species are preferably adsorbed on the surface due to electrostatic 


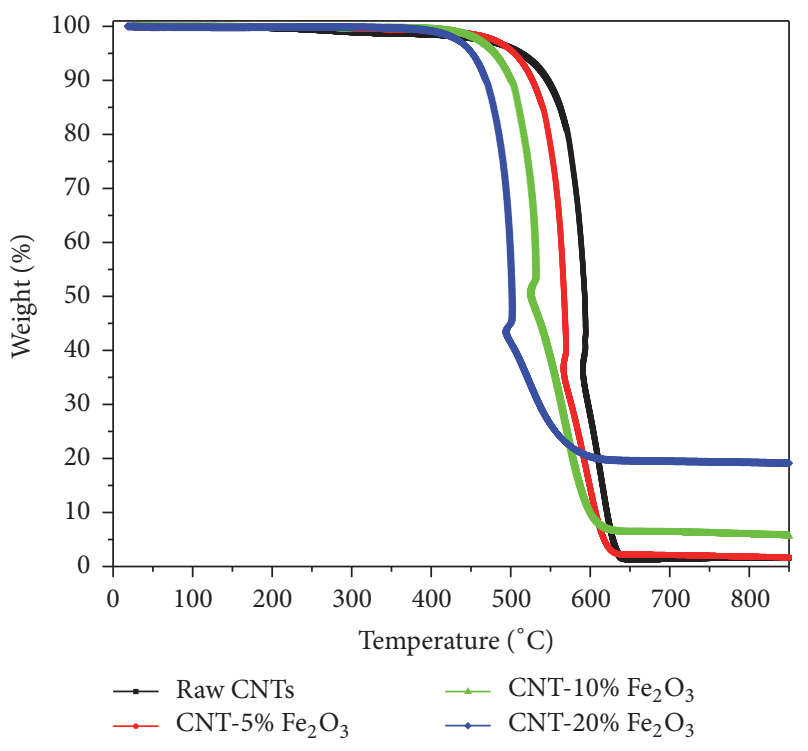

FIGURE 4: TGA analysis of raw CNTs and CNT-5\% iron oxide, CNT$10 \%$ iron oxide, and CNT-20\% iron oxide.

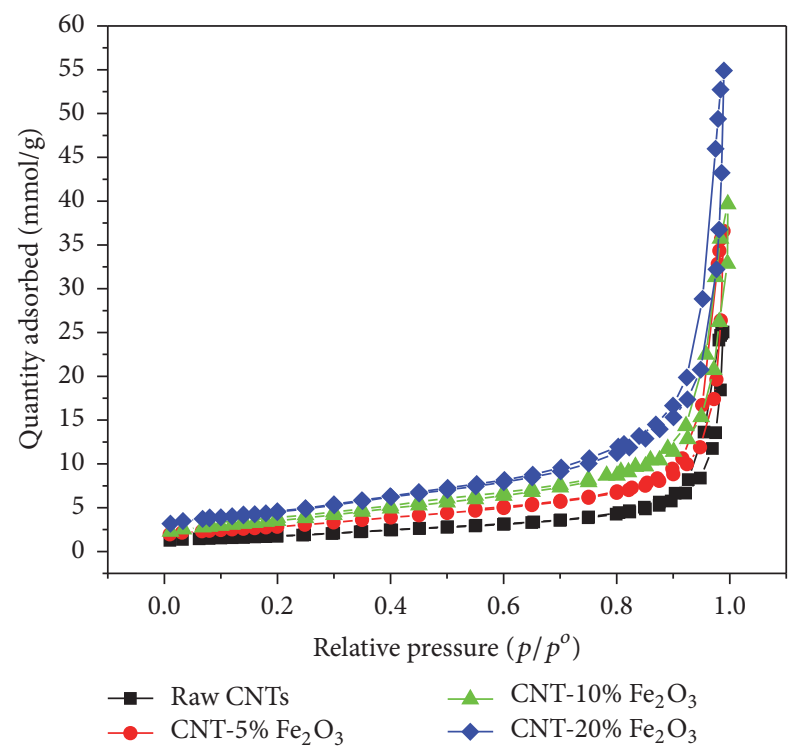

FIgURE 5: BET adsorption of $\mathrm{N}_{2}$ at $77 \mathrm{~K}$ for raw CNTs and CNT-5\% iron oxide, CNT-10\% iron oxide, and CNT-20\% iron oxide.

attractions [8, 46]. Monteil-Rivera et al. [47], however, reported that Se removal by hydroxyapatite increases with $\mathrm{pH}$ from $\mathrm{pH} 7$ to 8.5 , and it decreases above $\mathrm{pH}$ 8.5. In general, the adsorption capacity of Se was decreased slightly upon increasing the $\mathrm{pH}$ of solution. This might be due to the increase in the negative charge of the adsorbent surface and the consequent competition between the $\mathrm{OH}^{-}$ions and selenium ions for the available adsorption sites $[44,45]$. Figure 7 also reveals that raw CNTs were not efficient in removing Se ions from solution as shown in the flat trend that it depicts in Figure 6. The adsorption of selenium was less than $1 \%$ at $\mathrm{pH}$ between 1 and 2 . Negligible (close to zero) was recorded at $\mathrm{pH}$ of 2 . In contrast, it can be seen from the

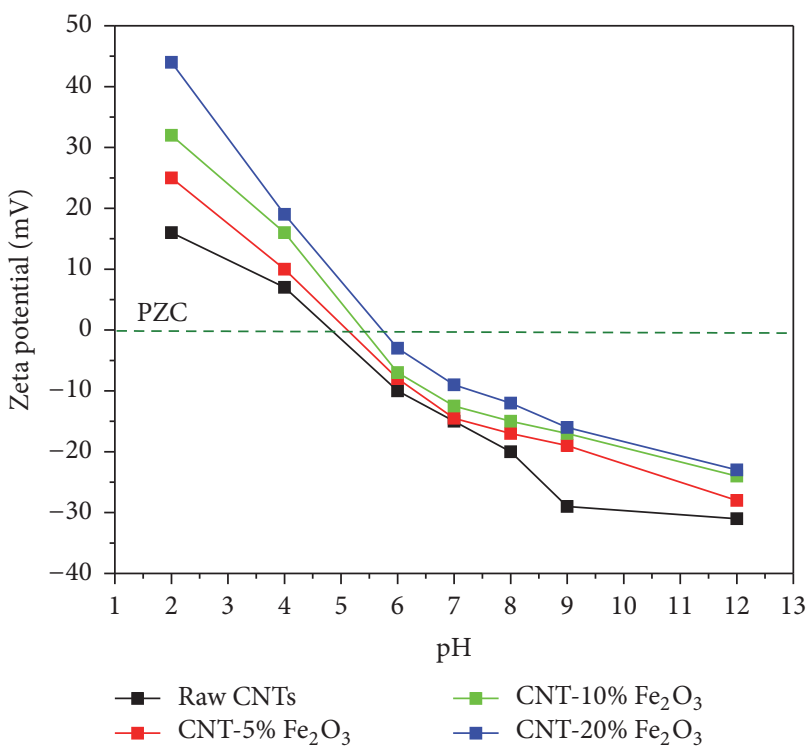

FIGURE 6: Zeta potential of raw CNTs and CNTs impregnated with $1 \%, 10 \%$, and $20 \% \mathrm{Fe}_{2} \mathrm{O}_{3}$.

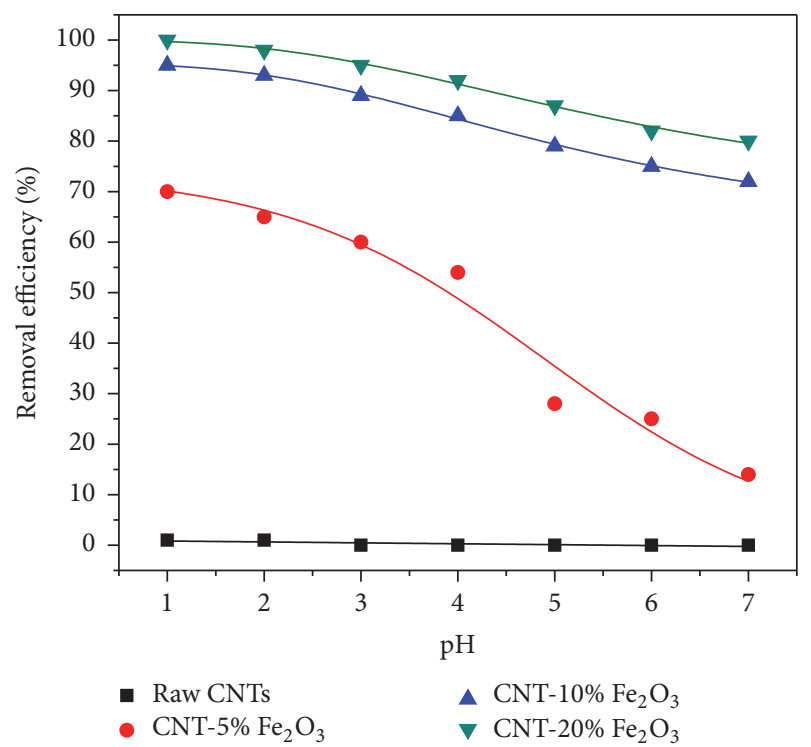

Figure 7: Effect of $\mathrm{pH}$ on the removal of selenium ions by raw and impregnated CNTs with different loading of iron oxide (agitation speed $=50 \mathrm{rpm}, \mathrm{CNTs}$ dosage $=10 \mathrm{mg}$, time $=6 \mathrm{hr}$, and initial concentration $=1 \mathrm{ppm}$ ).

trends in Figure 7 that vast improvement on the removal of Se from solution was achieved upon impregnating the surface of raw CNTs with iron oxide.

The percentage of iron oxide loading on the CNTs surface influenced the removal rate of Se. In general, it was observed at $20 \%$ loading rate that near $100 \%$ removal of Se was achieved compared to $93 \%$ and $65 \%$ for a loading rate of 10 and $5 \%$ iron oxide, respectively, at a $\mathrm{pH}$ of 1 for example. A number of factors may be attributed to this marked change. For example, the attachment of iron oxide particles onto the 


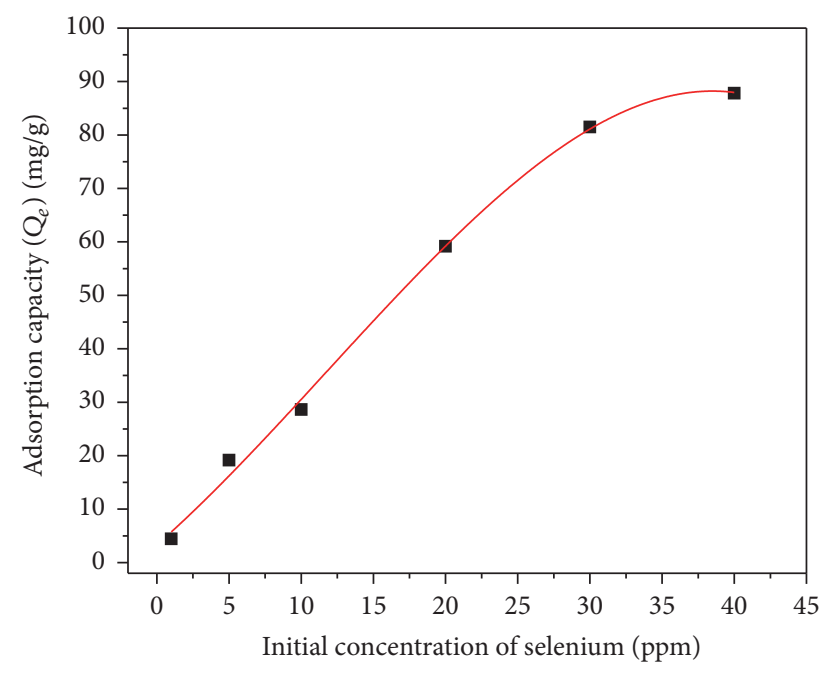

FIGURE 8: Effect of initial concentration of selenium on adsorption capacity of CNTs- $20 \%$ iron oxide (agitation speed $=150 \mathrm{rpm}, \mathrm{pH}=$ 6 , CNTs dosage $=10 \mathrm{mg}$, and time $=6 \mathrm{hr}$ ).

surface of CNTs may provide ample adsorption sites for the selenium ions to interact with. Also, it is well known that surfaces of metal oxides nanoparticles in aqueous solution are covered with hydroxyl groups [18]. Therefore, anion adsorption occurs by positive adsorbent surface charge (less negative sign compared to anion). Generally, increasing the $\mathrm{pH}$ causes decrease in the adsorbent surface charge and, accordingly, decreases in the adsorbent capacity $[18,39,54]$. As a result, when $\mathrm{pH}$ is increased the adsorbent surface is negatively charged (more negative sign) and leads to repulsion between negatively charged adsorbent particles and selenium anions. This repulsion causes termination of the adsorption process and also leads to the release of adsorbed selenium anions on surface of CNTs at higher $\mathrm{pH}$ to the water (desorption process). Based on the results reported in Figure 7, CNTs impregnated with $20 \mathrm{wt}$ \% of iron oxide were selected in the later experiments to study the effects of other variables such as the initial Se concentration, CNTs dosage, contact time, and kinetics and isotherms models.

3.3. Effect of Initial Concentration. Figure 8 depicts the impact of initial Se concentration on the adsorption capacity of iron oxide impregnated CNTs. In general, the trend showed a marked increase of adsorption capacity with the increase in Se initial concentration. Figure 8 shows that at Se initial concentration between 5 and $20 \mathrm{ppm}$, the adsorption rate was steep and the adsorption was fast as can be seen from the slope of the first trend line. Above $20 \mathrm{pmm}$ the adsorption slowed down and a plateau (second trend line) can be observed. The decline in the rate of adsorption at initial concentrations higher (as can be seen from the slope of the trend line) than $30 \mathrm{ppm}$ (Figure 8 ) may be attributed to the saturation of all adsorption sites on the surface of CNTs. The higher adsorption capacity at higher Se concentration may be due to increase in the mass transfer (driving force) of selenium ions towards the iron oxide impregnated CNTs

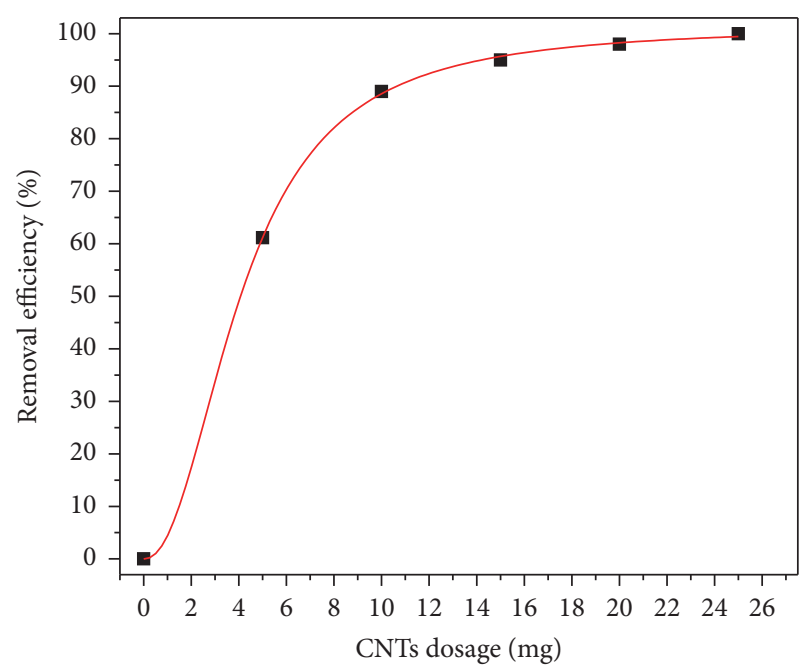

Figure 9: Effect of CNTs-20\% iron oxide dosage on selenium removal (agitation speed $=150 \mathrm{rpm}, \mathrm{pH}=6$, time $=6 \mathrm{hr}$, and initial concentration $=1 \mathrm{ppm})$.

surfaces [18]. The highest adsorption capacity was about $88 \mathrm{mg} / \mathrm{g}$ at an initial Se concentration of $40 \mathrm{ppm}$ as shown in Figure 8.

3.4. Effect of CNTs Dosage. The amount of CNTs added to the solution was varied between 5 and $25 \mathrm{mg}$ in order to study the required optimum amount of adsorbent required to carry out the adsorption duty. In the experiments, the contact time, agitation speed, and $\mathrm{pH}$ were kept constant at $6 \mathrm{hr}, 150 \mathrm{rpm}$, and 6, respectively. The experimental results are shown in Figure 9. Adsorption percentage (\%) of selenium was plotted as a function of adsorbent dosage. Selenium ions adsorption was increased with increasing CNTs dosage due to the increase in the adsorption sites on CNTs surfaces resulting in the increase amount of adsorbed selenite ions. Selenium ions were completely removed from the solution using only $25 \mathrm{mg}$ of CNTs. Therefore, the results show that the impregnated CNTs were suitable to adsorb selenium ions completely when there was sufficient CNTs surface area in the solution. Although the data was not shown here, the adsorption capacity was high at low dosages and keeps reducing at higher dosages. It is clearly agreed that as adsorbent dosage increases, the number of available adsorption sites increases, too. Alternatively, the decrease in adsorption capacity with increase in the adsorbent dosage is mostly related to the unsaturated nature of the adsorption sites through the adsorption process.

3.5. Effect of Contact Time. The effect of contact time on the adsorption of selenium ions is presented in Figure 10. It can be clearly seen that the rate of adsorption of selenium increased at initial period of contact time and then it decreased gradually with time until the adsorption reached an equilibrium point. The adsorption of selenium has increased rapidly during the first 30 minutes to reach about $65 \%$ removal. After that a slight increase was observed in the adsorption to 


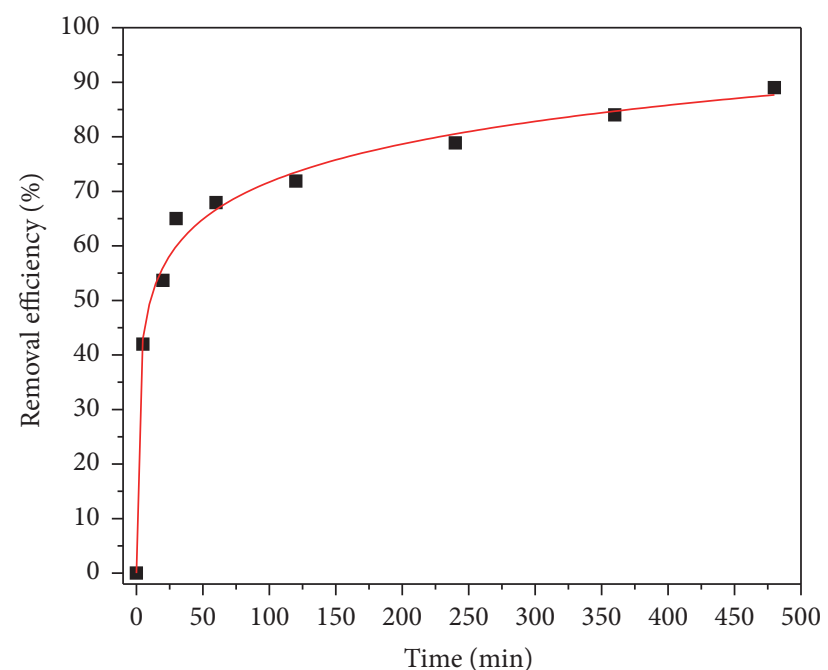

FIgURE 10: Effect of contact time on selenium removal (agitation speed $=150 \mathrm{rpm}, \mathrm{pH}=6, \mathrm{CNTs}$ dosage $=10 \mathrm{mg}$, and initial concentration $=1 \mathrm{ppm}$ ).

reach the maximum removal of selenium within four hours. The fast rate and then slow rate of adsorption suggest that selenium ions were first adsorbed on exterior surfaces of the CNTs during the initial time of contact. When the exterior surface gets saturated, the selenium ions diffused into the pores of the CNTs and were adsorbed at the interior surface of the CNTs.

3.6. Adsorption Kinetic Models. The modeling of the kinetics for selenium adsorption on CNTs was investigated using pseudo-first-order and pseudo-second-order kinetic models. Linearized plots of the two models are shown in Figure 11.

From Figure 11, the selenium adsorption on $\mathrm{Fe}_{2} \mathrm{O}_{3}$ impregnated CNTs does not fit very well to the pseudo-firstorder model, as the $R^{2}$ values are less than 0.5 . On the other hand, it does fit perfectly the pseudo-second-order model with $R^{2}$ value being almost 1 . The rate constant for the $20 \%$ $\mathrm{Fe}_{2} \mathrm{O}_{3}$ loaded CNTs is found to be $0.016 \mathrm{~g} / \mathrm{mg} \cdot \mathrm{h}$.

The result obtained in this study is in good agreement with those reported in literature as most of the solid-liquid adsorption processes tend to conform to the pseudo-secondorder model. Moreover, the pseudo-second-order model in this study can be defended by two-step linear relationship supporting the chemisorption nature of the process which is considered as rate-controlling mechanism as well [55]. The two-step linear mechanism between the composite CNTs (indicated as $\mathrm{C}$ and $\mathrm{XC}$ as activate adsorption site on CNTs) and Se ions is as follows:

$$
\begin{gathered}
2 \mathrm{C}+\mathrm{Se}^{2+} \longrightarrow \mathrm{Se} \\
2 \mathrm{XC}+\mathrm{Se}^{2+} \longrightarrow \mathrm{SeC}_{2}+2 \mathrm{X}^{+} .
\end{gathered}
$$

As it was found in Figure 11, the adsorption is pseudo-secondorder and the rate-limiting step is the chemical adsorption between Se ions and surface of CNTs through sharing or the exchange of electrons. Similar trends are reported for
TABLE 2: Parameters of Langmuir and Freundlich adsorption isotherm models of selenium.

\begin{tabular}{lcccccc}
\hline \multicolumn{3}{c}{ Langmuir } & \multicolumn{4}{c}{ Freundlich } \\
$Q_{m}(\mathrm{mg} / \mathrm{g})$ & $K_{L}\left(\mathrm{Lmg}^{-1}\right)$ & $R^{2}$ & $n$ & $K_{f}\left(\mathrm{mg}^{(1-1 / n)} \mathrm{L}^{1 / n} \mathrm{~g}^{-1}\right)$ & $R^{2}$ \\
\hline 111 & 0.158 & 0.879 & 1.74 & 16 & 0.98 \\
\hline
\end{tabular}

selenium ion adsorption in literature where the adsorption mechanism fit to pseudo-second-order model $[38,39]$.

3.7. Adsorption Isotherms Models. The adsorption data is modeled using the Freundlich and Langmuir isotherm models. As shown in Figure 12, the ability of the Freundlich model to fit the experimental data was studied by generating a plot of $\ln Q_{e}$ versus $\ln C_{e}$ with the intercept value of $K_{f}$ and the slope of $n$. It can be observed from Table 3 and Figure 12 that Freundlich isotherm model best fit the data $\left(R^{2}=0.98\right)$. From Figure 12(a) the Freundlich constants $K_{f}$ and $n$ for the CNTs were found to be 16 and 1.74, respectively. The value of $n$ or slope of the fit is an indication of sorption intensity or surface heterogeneity. When the slope gets closer to zero, the system tends to become more heterogeneous and a value of the slope greater than unity implies a favorable process and indicative of cooperative sorption. Therefore, as value of $\mathrm{n}$ increases, the sorption process between selenium ion and CNTs is more favorable and this means there is better bonding between sorbent and selenium. However, the Langmuir isotherm model (Figure 12(a)) fit reasonably $R^{2}$ value of 0.879 . The maximum adsorption capacity of the iron oxide impregnated CNTs, as predicted by isotherm model, was found to be $111 \mathrm{mg} / \mathrm{g}$.

Interestingly, composite made of CNTs and iron oxide nanoparticle showed very superior adsorption capacity compared to each one of the mentioned adsorbent in Table 2, where the capacity could reach maximum of $111 \mathrm{mg} / \mathrm{g}$ for selenium removal. There are few factors which contributed to the very high adsorption capacity compared to other materials in Table 3. Superior surface area, high zeta potential, and special surface structure of CNTs suggest that CNTs have great potential for use as contaminant adsorbents in wastewater treatment. The only limiting factor which might affect usage of CNTs in the application such as environmental protection or water treatment is their production cost. It is not very far if we predict that the cost will further reduce by advancement in technology and CNTs then could be one of the potential for application such as water treatment.

\section{Conclusions}

The study revealed that CNTs impregnated with $20 \mathrm{wt} . \%$ of iron oxide showed $100 \%$ removal of selenium ions in 6 hours with an initial concentration of $1 \mathrm{ppm}$ at $\mathrm{pH} 6$, adsorbent dosage of $25 \mathrm{mg}$, and agitation speed of $150 \mathrm{rpm}$. The adsorption data very well fitted to the Freundlich model with maximum adsorption capacity of the iron oxide impregnated CNTs predicted by Langmuir isotherm model 


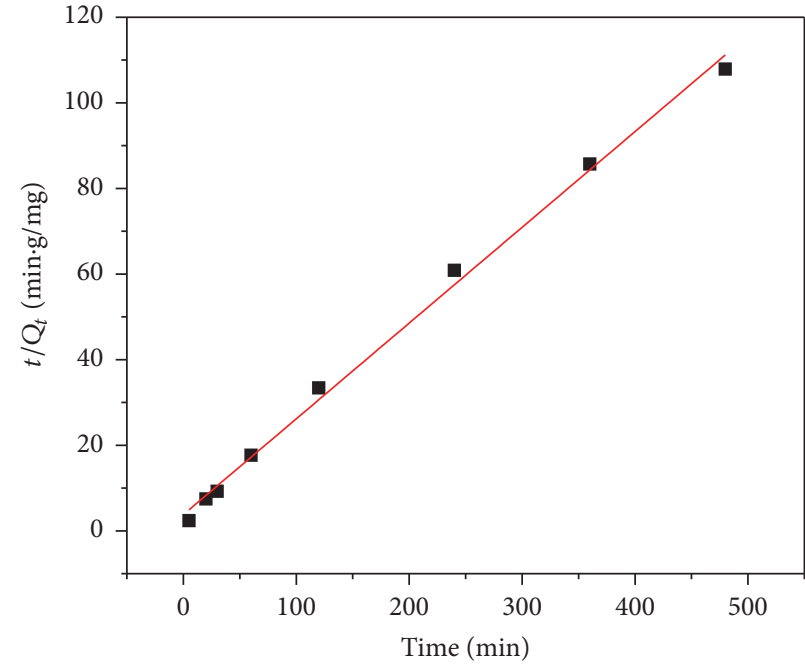

(a)

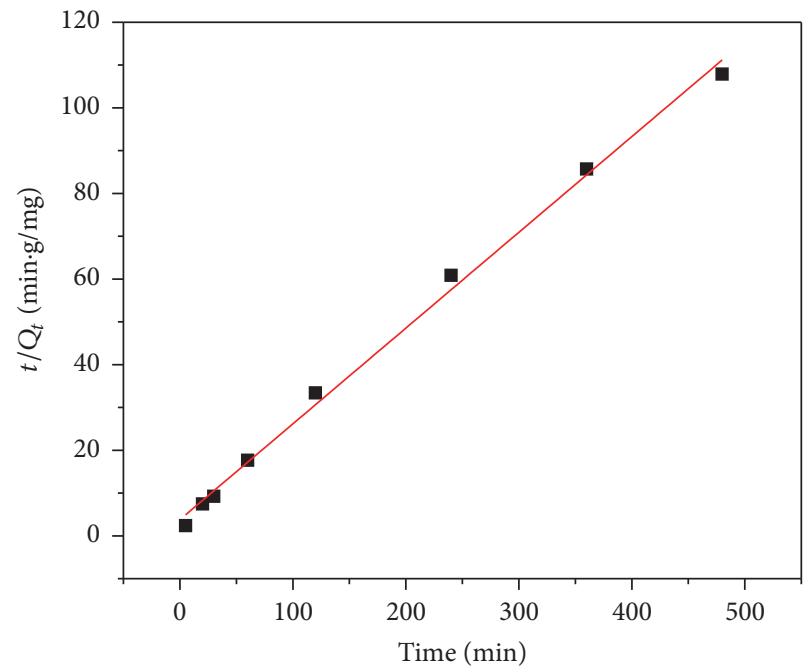

(b)

Figure 11: Adsorption kinetic for selenium removal: (a) pseudo-first-order and (b) pseudo-second-order model (agitation speed = $150 \mathrm{rpm}$, $\mathrm{pH}=6$, CNTs dosage $=10 \mathrm{mg}$, and initial concentration $=1 \mathrm{ppm})$.

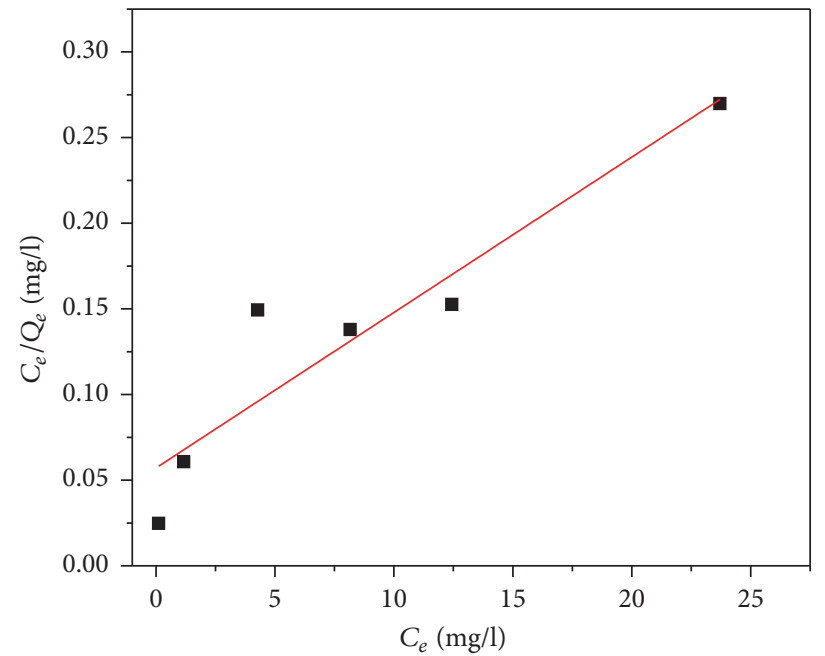

(a)

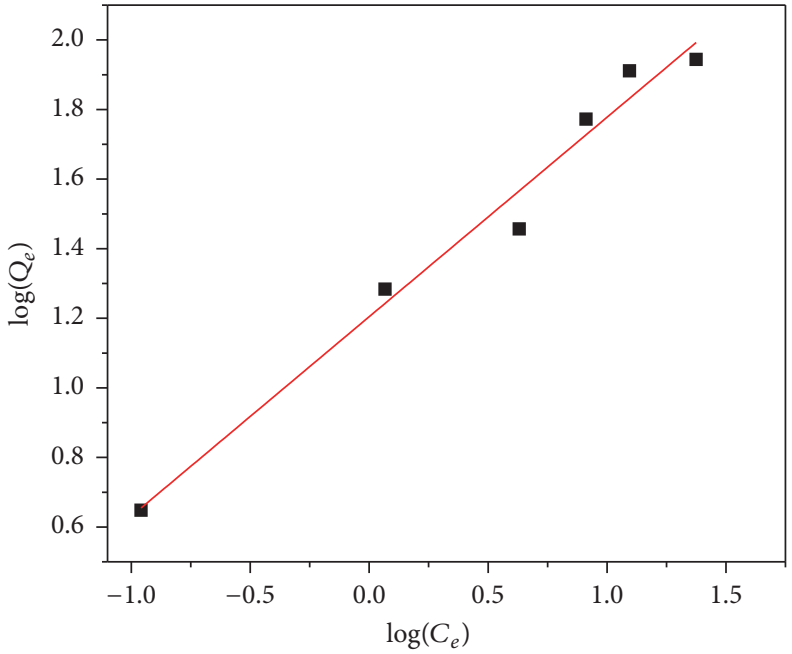

(b)

Figure 12: Adsorption isotherm models of selenium: (a) Langmuir and (b) Freundlich.

TABLE 3: Adsorption capacity of different materials for adsorption of selenium from water.

\begin{tabular}{|c|c|c|c|}
\hline Type of adsorbent & Experimental conditions & $\begin{array}{l}\text { Max. adsorption } \\
\text { capacity }(\mathrm{mg} / \mathrm{g})\end{array}$ & Reference \\
\hline Iron oxide nanoparticle & $\mathrm{pH}=4$, initial concentration $=0.01 \mathrm{mg} / \mathrm{L}$ & 15.1 & {$[8]$} \\
\hline Chitosan-clay composite & $\mathrm{pH}=4$, initial concentration $=0.1 \mathrm{mg} / \mathrm{L}, T=30^{\circ} \mathrm{C}$ & 18.4 & {$[15]$} \\
\hline Iron-coated GAC & $\mathrm{pH}=2-8$, initial concentration $=2 \mathrm{mg} / \mathrm{L}, T=45^{\circ} \mathrm{C}$ & 2.89 & [38] \\
\hline Nanocrystalline hydroxyapatite & $\mathrm{pH}=5$, initial concentration $=0.01 \mathrm{mg} / \mathrm{L}, T=30^{\circ} \mathrm{C}$ & 1.94 & [39] \\
\hline Aluminum oxide coated sand & $\mathrm{pH}=4.80$, initial concentration $=1.2 \mathrm{mM}$ & 1.08 & {$[40]$} \\
\hline Sulfuric acid treated rice husk & $\mathrm{pH}=1.5$, initial concentration $=100 \mathrm{mg} / \mathrm{L} \mathrm{T}=45^{\circ} \mathrm{C}$ & 40.92 & {$[41]$} \\
\hline Iron oxide impregnated CNTs & $\mathrm{pH}=6, \mathrm{CNTs}$ dosage $=10 \mathrm{mg}$ and initial concentration $=1 \mathrm{ppm}$ & 111 & This study \\
\hline
\end{tabular}


to be $111 \mathrm{mg} / \mathrm{g}$. The date was correlated very well to pseudosecond-order kinetic model and rate of constant was found to be $0.016 \mathrm{~g} / \mathrm{mg} \cdot \mathrm{h}$. The highest adsorption capacity of iron oxide impregnated CNTs suggested that it can be employed effectively for the removal of selenium ions from water.

\section{Conflicts of Interest}

The authors declare that they have no conflicts of interest regarding the publication of this paper.

\section{Acknowledgments}

The authors would like to acknowledge the support provided by King Fahd University of Petroleum \& Minerals (KFUPM) for sponsoring and funding this work.

\section{References}

[1] J. Das, D. Das, G. P. Dash, and K. M. Parida, "Studies on $\mathrm{Mg} / \mathrm{Fe}$ hydrotalcite-like-compound (HTlc): I. Removal of inorganic selenite $\left(\mathrm{SeO}_{3}^{2-}\right)$ from aqueous medium," Journal of Colloid and Interface Science, vol. 251, no. 1, pp. 26-32, 2002.

[2] K. S. Dhillon and S. K. Dhillon, "Selenium in groundwater and its contribution towards daily dietary Se intake under different hydrogeological zones of Punjab, India," Journal of Hydrology, vol. 533, pp. 615-626, 2016.

[3] J. Lessa, A. Araujo, G. Silva, L. Guilherme, and G. Lopes, "Adsorption-desorption reactions of selenium (VI) in tropical cultivated and uncultivated soils under Cerrado biome," Chemosphere, vol. 164, pp. 271-277, 2016.

[4] H. Robberecht and R. Van Grieken, "Selenium in environmental waters: determination, speciation and concentration levels," Talanta, vol. 29, no. 10, pp. 823-844, 1982.

[5] S. Santos, G. Ungureanu, R. Boaventura, and C. Botelho, "Selenium contaminated waters: an overview of analytical methods, treatment options and recent advances in sorption methods," Science of the Total Environment, vol. 521-522, no. 1, pp. 246-260, 2015.

[6] L. C. Tan, Y. V. Nancharaiah, E. D. van Hullebusch, and P. N. Lens, "Selenium: environmental significance, pollution, and biological treatment technologies," Biotechnology Advances, vol. 34, no. 5, pp. 886-907, 2016.

[7] C. Hu, Q. Chen, G. Chen, H. Liu, and J. Qu, "Removal of Se(IV) and $\mathrm{Se}(\mathrm{VI})$ from drinking water by coagulation," Separation and Purification Technology, vol. 142, pp. 65-70, 2015.

[8] G. Zelmanov and R. Semiat, "Selenium removal from water and its recovery using iron $\left(\mathrm{Fe}^{3+}\right)$ oxide/hydroxide-based nanoparticles sol (NanoFe) as an adsorbent," Separation and Purification Technology, vol. 103, pp. 167-172, 2013.

[9] N. Rajamohan and M. Rajasimman, "Biosorption of Selenium using activated plant based sorbent-effect of variables, isotherm and kinetic modeling," Biocatalysis and Agricultural Biotechnology, vol. 4, no. 4, pp. 795-800, 2015.

[10] H. G. Gorchev and G. Ozolins, "WHO guidelines for drinkingwater quality," WHO Chronicle, vol. 38, no. 3, pp. 104-108, 2011.

[11] G. Kallis and D. Butler, "The EU water framework directive: measures and implications," Water Policy, vol. 3, no. 2, pp. 125$142,2001$.
[12] G. Gonzalez-Gil, P. N. L. Lens, and P. E. Saikaly, "Selenite reduction by anaerobic microbial aggregates: Microbial community structure, and proteins associated to the produced selenium spheres," Frontiers in Microbiology, vol. 7, article 571, 2016.

[13] T. Kagami, T. Narita, M. Kuroda et al., "Effective selenium volatilization under aerobic conditions and recovery from the aqueous phase by Pseudomonas stutzeri NT-I," Water Research, vol. 47, no. 3, pp. 1361-1368, 2013.

[14] L. C. Staicu, E. D. Van Hullebusch, M. A. Oturan, C. J. Ackerson, and P. N. L. Lens, "Removal of colloidal biogenic selenium from wastewater," Chemosphere, vol. 125, pp. 130-138, 2015.

[15] N. Bleiman and Y. G. Mishael, "Selenium removal from drinking water by adsorption to chitosan-clay composites and oxides: batch and columns tests," Journal of Hazardous Materials, vol. 183, no. 1-3, pp. 590-595, 2010.

[16] Y. Fu, J. Wang, Q. Liu, and H. Zeng, "Water-dispersible magnetic nanoparticle-graphene oxide composites for selenium removal," Carbon, vol. 77, pp. 710-721, 2014.

[17] J. H. Kwon, L. D. Wilson, and R. Sammynaiken, "Sorptive uptake of selenium with magnetite and its supported materials onto activated carbon," Journal of Colloid and Interface Science, vol. 457, pp. 388-397, 2015.

[18] A. W. Lounsbury, J. S. Yamani, C. P. Johnston, P. LareseCasanova, and J. B. Zimmerman, "The role of counter ions in nano-hematite synthesis: implications for surface area and selenium adsorption capacity," Journal of Hazardous Materials, vol. 310, pp. 117-124, 2016.

[19] L. D. Mafu, B. B. Mamba, and T. A. M. Msagati, "Synthesis and characterization of ion imprinted polymeric adsorbents for the selective recognition and removal of arsenic and selenium in wastewater samples," Journal of Saudi Chemical Society, vol. 20, no. 5, pp. 594-605, 2013.

[20] V. C. Schwindt, J. S. Ardenghi, P. Bechthold et al., "Selenium adsorption at different coverages on $\mathrm{Fe}(100)$ and $\mathrm{Fe}(111)$ : a DFT study," Applied Surface Science, vol. 315, no. 1, pp. 252-260, 2014.

[21] M. Lenz and P. N. L. Lens, "The essential toxin: the changing perception of selenium in environmental sciences," Science of the Total Environment, vol. 407, no. 12, pp. 3620-3633, 2009.

[22] M. O. M. Sharrad, H. Liu, and M. Fan, "Evaluation of FeOOH performance on selenium reduction," Separation and Purification Technology, vol. 84, pp. 29-34, 2012.

[23] S. Klas and D. W. Kirk, "Understanding the positive effects of low $\mathrm{pH}$ and limited aeration on selenate removal from water by elemental iron," Separation and Purification Technology, vol. 116, pp. 222-229, 2013.

[24] P. J. F. Harris, Carbon Nanotube Science: Synthesis, Properties and Applications, Cambridge University Press, Cambridge, UK, 2009.

[25] D. Kang, X. Yu, M. Ge, F. Xiao, and H. Xu, "Novel Al-doped carbon nanotubes with adsorption and coagulation promotion for organic pollutant removal," Journal of Environmental Sciences, vol. 54, pp. 1-12, 2017.

[26] A. K. Fard, G. Mckay, Y. Manawi, Z. Malaibari, and M. A. Hussien, "Outstanding adsorption performance of high aspect ratio and super-hydrophobic carbon nanotubes for oil removal," Chemosphere, vol. 164, pp. 142-155, 2016.

[27] X. Liu, M. Wang, S. Zhang, and B. Pan, "Application potential of carbon nanotubes in water treatment: a review," Journal of Environmental Sciences, vol. 25, no. 7, pp. 1263-1280, 2013.

[28] Ihsanullah, F. A. Al-Khaldi, B. Abu-Sharkh et al., "Effect of acid modification on adsorption of hexavalent chromium 
$(\mathrm{Cr}(\mathrm{VI}))$ from aqueous solution by activated carbon and carbon nanotubes," Desalination and Water Treatment, vol. 57, no. 16, pp. 7232-7244, 2016.

[29] Y.-H. Li, J. Ding, Z. Luan et al., "Competitive adsorption of $\mathrm{Pb}^{2+}$, $\mathrm{Cu}^{2+}$ and $\mathrm{Cd}^{2+}$ ions from aqueous solutions by multiwalled carbon nanotubes," Carbon, vol. 41, no. 14, pp. 2787-2792, 2003.

[30] G. P. Rao, C. Lu, and F. Su, "Sorption of divalent metal ions from aqueous solution by carbon nanotubes: a review," Separation and Purification Technology, vol. 58, no. 1, pp. 224-231, 2007.

[31] F. Yu, Y. Wu, J. Ma, and C. Zhang, "Adsorption of lead on multi-walled carbon nanotubes with different outer diameters and oxygen contents: kinetics, isotherms and thermodynamics," Journal of Environmental Sciences, vol. 25, no. 1, pp. 195-203, 2013.

[32] N. M. M. Fourier, J. N. Sahu, E. C. Abdullah, and N. S. Jayakumar, "Rapid adsorption of toxic $\mathrm{Pb}$ (II) ions from aqueous solution using multiwall carbon nanotubes synthesized by microwave chemical vapor deposition technique," Journal of Environmental Sciences, vol. 45, pp. 143-155, 2016.

[33] A. Abbas, B. A. Abussaud, Ihsanullah, N. A. H. Al-Baghli, M. Khraisheh, and M. A. Atieh, "Benzene removal by iron oxide nanoparticles decorated carbon nanotubes," Journal of Nanomaterials, vol. 2016, Article ID 5654129, 10 pages, 2016.

[34] H. A. Asmaly, B. Abussaud, Ihsanullah et al., "Evaluation of micro- and nano-carbon-based adsorbents for the removal of phenol from aqueous solutions," Toxicological and Environmental Chemistry, vol. 97, no. 9, pp. 1164-1179, 2015.

[35] Ihsanullah, H. A. Asmaly, T. A. Saleh, T. Laoui, V. K. Gupta, and M. A. Atieh, "Enhanced adsorption of phenols from liquids by aluminum oxide/carbon nanotubes: comprehensive study from synthesis to surface properties," Journal of Molecular Liquids, vol. 206, pp. 176-182, 2015.

[36] H. Ding, X. Li, J. Wang, X. Zhang, and C. Chen, "Adsorption of chlorophenols from aqueous solutions by pristine and surface functionalized single-walled carbon nanotubes," Journal of Environmental Sciences, vol. 43, pp. 187-198, 2016.

[37] A. Kayvani Fard, T. Rhadfi, G. Mckay et al., "Enhancing oil removal from water using ferric oxide nanoparticles doped carbon nanotubes adsorbents," Chemical Engineering Journal, vol. 293, pp. 90-101, 2016.

[38] N. Zhang, L.-S. Lin, and D. Gang, "Adsorptive selenite removal from water using iron-coated GAC adsorbents," Water Research, vol. 42, no. 14, pp. 3809-3816, 2008.

[39] S. Kongsri, K. Janpradit, K. Buapa, S. Techawongstien, and S. Chanthai, "Nanocrystalline hydroxyapatite from fish scale waste: preparation, characterization and application for selenium adsorption in aqueous solution," Chemical Engineering Journal, vol. 215-216, pp. 522-532, 2013.

[40] W.-H. Kuan, S.-L. Lo, M. K. Wang, and C.-F. Lin, "Removal of $\mathrm{Se}(\mathrm{IV})$ and $\mathrm{Se}(\mathrm{VI})$ from water by aluminum-oxide-coated sand," Water Research, vol. 32, no. 3, pp. 915-923, 1998.

[41] E. I. El-Shafey, "Sorption of Cd(II) and Se(IV) from aqueous solution using modified rice husk," Journal of Hazardous Materials, vol. 147, no. 1-2, pp. 546-555, 2007.

[42] J. H. Lehman, M. Terrones, E. Mansfield, K. E. Hurst, and V. Meunier, "Evaluating the characteristics of multiwall carbon nanotubes," Carbon, vol. 49, no. 8, pp. 2581-2602, 2011.

[43] I. W. Chiang, B. E. Brinson, A. Y. Huang et al., "Purification and characterization of single-wall carbon nanotubes (SWNTs) obtained from the gas-phase decomposition of $\mathrm{CO}$ (HiPco process)," Journal of Physical Chemistry B, vol. 105, no. 35, pp. 8297-8301, 2001.
[44] R. Dobrowolski and M. Otto, "Preparation and evaluation of Fe-loaded activated carbon for enrichment of selenium for analytical and environmental purposes," Chemosphere, vol. 90, no. 2, pp. 683-690, 2013.

[45] M. Duc, G. Lefèvre, and M. Fédoroff, "Sorption of selenite ions on hematite," Journal of Colloid and Interface Science, vol. 298, no. 2, pp. 556-563, 2006.

[46] K.-H. Goh and T.-T. Lim, "Geochemistry of inorganic arsenic and selenium in a tropical soil: effect of reaction time, $\mathrm{pH}$, and competitive anions on arsenic and selenium adsorption," Chemosphere, vol. 55, no. 6, pp. 849-859, 2004.

[47] F. Monteil-Rivera, M. Fedoroff, J. Jeanjean, L. Minel, M.-G. Barthes, and J. Dumonceau, "Sorption of selenite $\left(\mathrm{SeO}_{3}^{2-}\right)$ on hydroxyapatite: an exchange process," Journal of Colloid and Interface Science, vol. 221, no. 2, pp. 291-300, 2000.

[48] A. Manceau and L. Charlet, "The mechanism of selenate adsorption on goethite and hydrous ferric oxide," Journal of Colloid And Interface Science, vol. 168, no. 1, pp. 87-93, 1994.

[49] K. F. Hayes, C. Papelis, and J. O. Leckie, "Modeling ionic strength effects on anion adsorption at hydrous oxide/solution interfaces," Journal of Colloid And Interface Science, vol. 125, no. 2, pp. 717-726, 1988.

[50] Y. Tianmeng, B. Liu, and J. Liu, "Adsorption of selenite and selenate by metal oxides studied with fluorescent DNA probes for analytical application," Journal of Analysis and Testing, vol. 1, article 2, 2017.

[51] Z. Nie, N. Finck, F. Heberling, T. Prüessmann, C. Liu, and J. Lutzenkirchen, "Adsorption of selenium and strontium on Goethite: an EXAFS study and surface complexation modeling of the ternary systems," Environmental Science and Technology, vol. 51, no. 7, pp. 3751-3758, 2017.

[52] S. O. Adio, M. H. Omar, M. Asif, and T. A. Saleh, "Arsenic and Selenium removal from water using Biosynthesized Nanoscale zero-valent iron: a factorial design analysis," Process Safety and Environmental Protection, vol. 107, pp. 518-527, 2017.

[53] M. Min, C. Shen, L. Fang et al., "Design of a selective regenerable cellulose microcolumn for selenium efficient recovery and economic determination," Chemical Engineering Research and Design, vol. 117, pp. 7773-783, 2017.

[54] D. S. Han, B. Batchelor, and A. Abdel-Wahab, "Sorption of selenium(IV) and selenium(VI) to mackinawite (FeS): effect of contact time, extent of removal, sorption envelopes," Journal of Hazardous Materials, vol. 186, no. 1, pp. 451-457, 2011.

[55] Y. S. Ho and G. McKay, "Pseudo-second order model for sorption processes," Process Biochemistry, vol. 34, no. 5, pp. 451$465,1999$. 

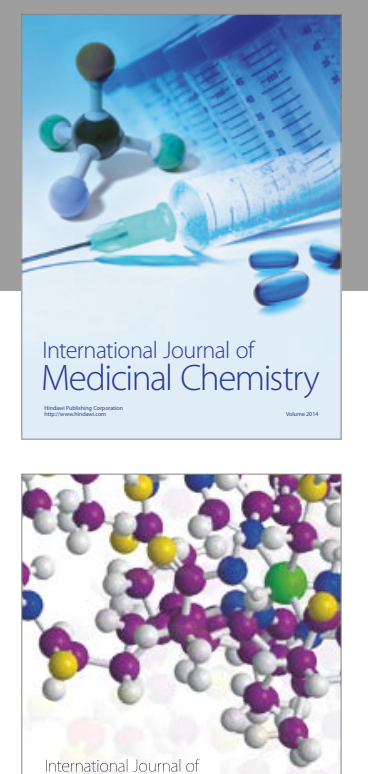

Carbohydrate Chemistry

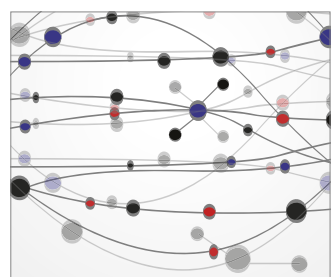

The Scientific World Journal
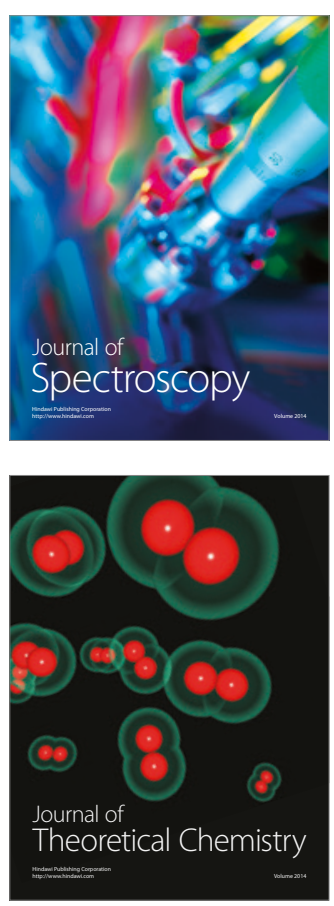
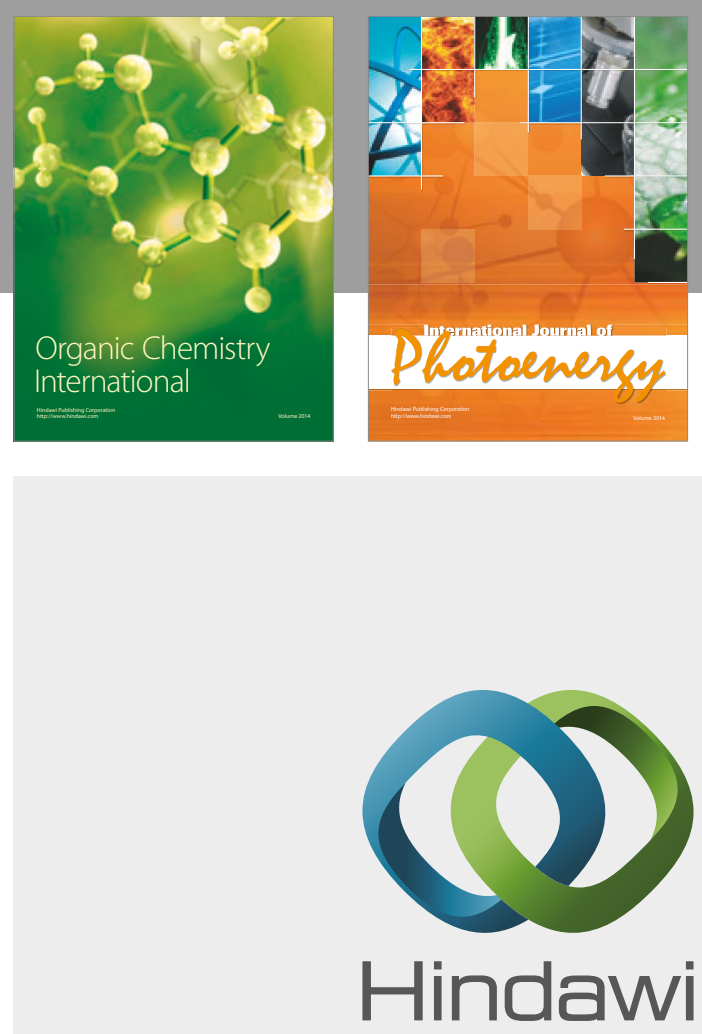

Submit your manuscripts at

https://www.hindawi.com

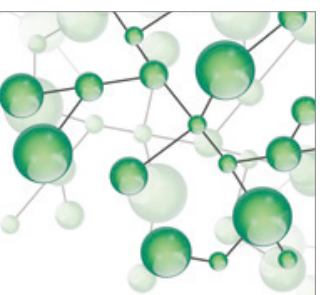

International Journal of

Inorganic Chemistry

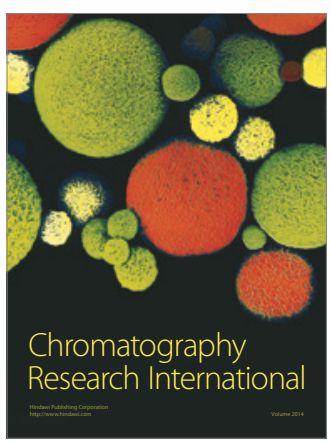

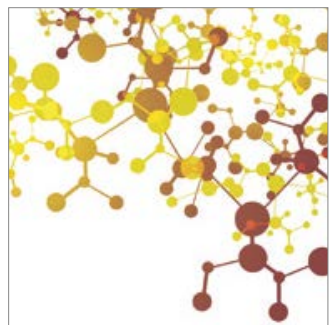

Applied Chemistry
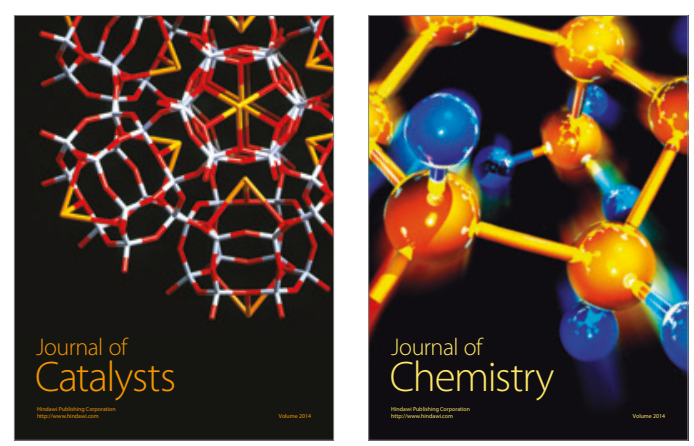
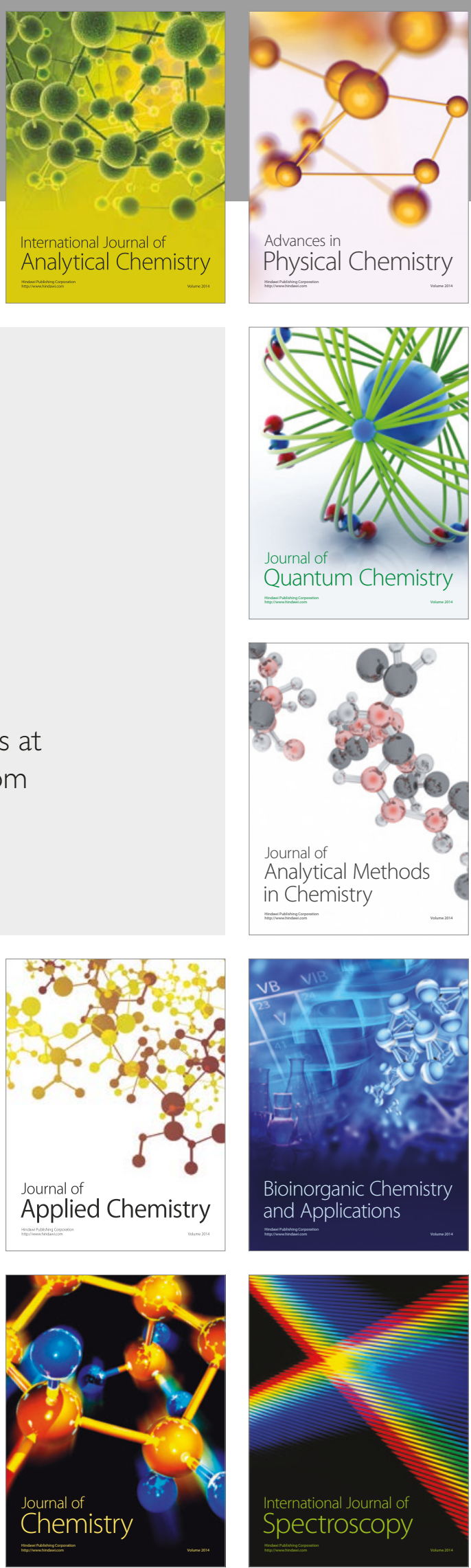